EPIDEMIOLOGICAL REVIEW

\title{
Recent trends in HIV and other STls in the United Kingdom: data to the end of 2002
}

\author{
A E Brown, K E Sadler, S E Tomkins, C A McGarrigle, D S LaMontagne, D Goldberg, P A Tookey, \\ B Smyth, D Thomas, G Murphy, J V Parry, B G Evans, O N Gill, F Ncube, K A Fenton
}

Sex Transm Infect 2004;80:159-166. doi: 10.1136/sti.2004.009571

Sexual health in the United Kingdom has deteriorated in recent years with further increases in HIV and other sexually transmitted infections (STIs) reported in 2002. This paper describes results from the available surveillance data in the United Kingdom from the Health Protection Agency and its national collaborators. The data sources range from voluntary reports of HIV/AIDS from clinicians, CD4 cell count monitoring, a national census of individuals living with HIV, and the Unlinked Anonymous Programme, to statutory reports of STIs from genitourinary medicine (GUM) clinics and enhanced STI surveillance systems. In 2002, an estimated 49500 adults aged over 15 years were living with HIV in the United Kingdom, of whom 31\% were unaware of their infection. Diagnoses of new HIV infections have doubled from 1997 to 2002, mainly driven by heterosexuals who acquired their infection abroad. HIV transmission also continues within the United Kingdom, particularly among homo/bisexual men who, in 2002, accounted for $80 \%$ of all newly diagnosed HIV infections acquired in the United Kingdom. New diagnoses of syphilis have increased eightfold, and diagnoses of chlamydia and gonorrhoea have doubled from 1997 to 2002 overall; STI rates disproportionately affect homo/bisexual men and young people. Effective surveillance is essential in the provision of timely information on the changing epidemiology of HIV and other STIs; this information is necessary for the targeting of prevention efforts and through providing baseline information against which progress towards targets can be monitored.

See end of article for authors' affiliations

Correspondence to: Alison Brown, HIV and STI Department

Communicable Disease

Surveillance Centre, 61 Colindale Avenue, London NW9 5EQ, UK; alison.

brown@hpa.org.uk

Accepted for publication 2 April 2004
$\mathrm{S}$ exual health in the United Kingdom has deteriorated in recent years. ${ }^{12}$ Increases in HIV and other sexually transmitted infections (STIs) have placed enormous pressure on existing sexual health services. ${ }^{3}$ Consequent delays in accessing diagnosis and care may in turn be facilitating infection transmission. Since 2001, a range of new initiatives aimed at improving sexual health have been established in the United Kingdom. In England, the implementation of the 10 year National Strategy for Sexual Health and HIV ${ }^{4}$ has seen the appointment of local sexual health leads in primary care trusts (PCTs) and the Independent Advisory
Group on Sexual Health'; greater investment in genitourinary medicine (GUM) clinics, and phased implementation of prevention interventions, such as the National Chlamydia Screening Programme, aimed at specific population risk groups. There have been similar strategies in other UK countries (Wales, ${ }^{6}$ Scotland, ${ }^{7}$ and Northern Ireland). ${ }^{8}$ The Health Select Committee report on Sexual Health, ${ }^{9}$ the All Party Parliamentary Group on AIDS report on Migration and HIV, ${ }^{10}$ and most recently the government's response to the Health Select Committee's report on sexual health ${ }^{11}$ have all drawn attention to the need for greater political will and investment in tackling HIV and STIs in the United Kingdom and globally.

Surveillance data have a key role in such strategies. The collection and analysis of data, in conjunction with the monitoring of trends with timely feedback provides information for the implementation and evaluation of these initiatives. Specifically, by highlighting where prevention efforts should be targeted and through providing baseline information against which progress towards targets can be monitored.

The immediate public health challenges facing sexual health in the United Kingdom include increasing incidence and prevalence of HIV and STIs; rising costs of HIV related care; variation in disease determinants and distribution; and the associated long term morbidity and mortality of these conditions. This paper summarises recent trends in the UK surveillance data for HIV and other STIs up until the end of 2002. ${ }^{12}$

\section{DATA SOURCES}

In the United Kingdom, the majority of STIs, including HIV, are diagnosed and treated in GUM clinics which form part of the National Health Service. Although diagnoses of many STIs (particularly chlamydia) occur in primary care and other community settings, ${ }^{13}$ only GUM clinics have statutory reporting of STIs to the Health Protection Agency and its collaborators by clinicians. The detailed methods of the HIV and STI surveillance systems in the United Kingdom have been described elsewhere ${ }^{12}$ and are briefly summarised here.

\section{HIV/AIDS reporting}

New diagnoses of HIV infections, AIDS cases, and deaths ${ }^{14}$ (HIV/AIDS reporting) are reported by laboratories and clinicians through voluntary reporting systems. The annual Survey of Prevalent HIV Infections Diagnosed (SOPHID) ${ }^{15}$ provides a census of the number of individuals 
living with diagnosed HIV infection and receiving care in England, Wales, and Northern Ireland. Longitudinal data on CD4 $\mathrm{T}$ lymphocytes ${ }^{16}$ (CD4 surveillance) are reported from laboratories in England, Wales and Scotland and are used to monitor trends in immunosuppression associated with HIV infection. In Scotland, these data are used to gauge the number of people in specialist HIV care.

\section{Unlinked anonymous HIV surveys}

The unlinked anonymous (UA) HIV surveys ${ }^{17}$ measure the prevalence of HIV, including undiagnosed HIV infections, in selected subgroups of the population. The unlinked anonymous survey of GUM clinic attendees (UA GUM survey) measures HIV prevalence in a high risk population (attendees of sentinel GUM clinics in the United Kingdom). ${ }^{18}$ In England, Wales, and Northern Ireland the incidence of HIV infection in homo/bisexual men included in the UA GUM survey has been determined by application of the Serological Testing Algorithm for Recent HIV Seroconversion (STARHS). ${ }^{19}$

Prevalence in the general population is measured by surveys of pregnant women (UA pregnant women surveyspregnant women attending antenatal care and women giving birth in England and Scotland). Live births to diagnosed HIV infected women in the United Kingdom are reported to the National Study of HIV in Pregnancy and Childhood. ${ }^{20}$ These reports are aligned with the overall prevalence estimates for HIV in pregnant women by geographical area, to produce estimates of the proportion of women giving birth who were diagnosed before antenatal attendances, diagnosed through antenatal testing, and who remained undiagnosed at delivery. ${ }^{21}$

\section{STI surveillance}

Statutory KC60 returns from all GUM clinics $^{12}$ in England, Wales, and Northern Ireland provide aggregate data on the total episodes of diagnosed STIs by sex and age group (and sexual orientation for selected conditions). The ISD(D) 5 returns system provides disaggregate data on all STI diagnoses in GUM clinics in Scotland. ${ }^{12}$ NHS laboratories throughout the United Kingdom provide voluntary electronic disaggregate reporting on laboratory diagnoses of selected STIs with age and sex information. Enhanced Syphilis Surveillance (ESS) collects further demographic and risk factor data in the United Kingdom, and is designed to improve interpretation of the incidence and distribution of infectious syphilis. ${ }^{22}$ The Gonococcal Resistance to Antimicrobials Surveillance Programme (GRASP) is a sentinel surveillance system for monitoring gonococcal antimicrobial resistance and collects detailed behavioural information on diagnoses of gonorrhoea in England. ${ }^{23}$

\section{Related surveillance techniques}

Estimates of the total number of HIV infected people in the United Kingdom ${ }^{24}$ were calculated by combining data from SOPHID (for diagnosed HIV infections) and the unlinked anonymous surveys (for undiagnosed HIV infections), with estimates of the size of the population in various exposure categories derived from the National Survey of Sexual Attitudes and Lifestyles (Natsal 2000), ${ }^{25}$ and census 2001 population estimates (Office for National Statistics).

Annual rates (cases/population) of diagnoses of STIs were calculated per 100000 people. The 2002 rates for all regions and countries in the United Kingdom were calculated by dividing the number of cases reported from GUM clinics in each area in 2002 by the mid-2002 population estimates from the Office for National Statistics (for homo/bisexual men population estimates were derived from Natsal $2000^{25}$ ). Descriptive epidemiology is the focus of the paper, but

\section{Previously undiagnosed HIV infection}

This includes both HIV infected individuals who were diagnosed with HIV at the episode of clinical care, and individuals who left clinical care remaining unaware of their infection, but excludes individuals whose HIV infection was diagnosed before the episode of clinical care

hypothesis tests have been used to supplement the data where appropriate using Stata 7 (StataCorp, 2001).

\section{OVERALL HIV/STI SURVEILLANCE TRENDS}

Estimates of the total prevalent infections indicate that at the end of 2002, 49500 adults aged over 15 were living with HIV
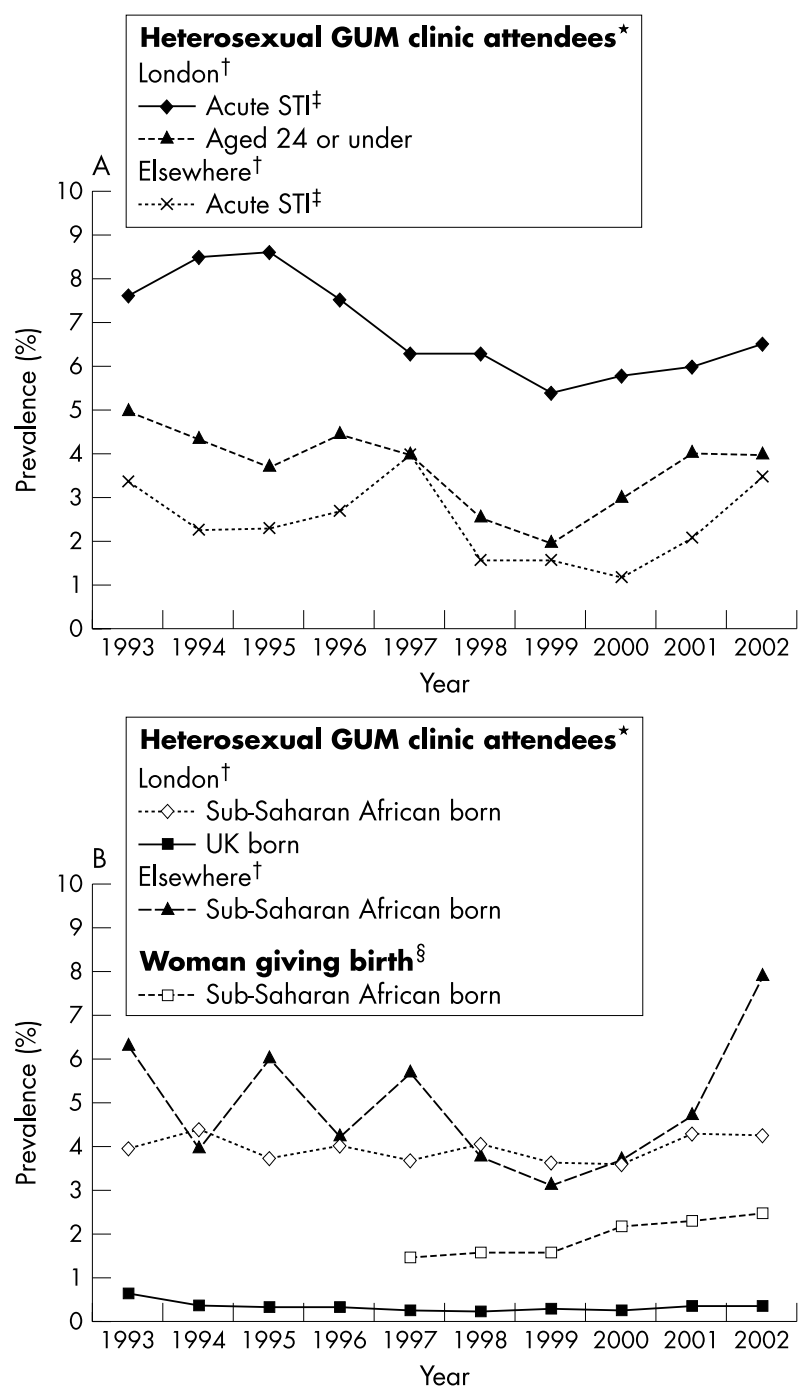

Figure 1 Prevalence of previously undiagnosed HIV infection in England, Wales, and Northern Ireland, 1993-2002. (A) Previously undiagnosed* HIV infection in homo/bisexual ment by clinical presentation and age group. (B) Previously undiagnosed ${ }^{*} \mathrm{HIV}$ infection in heterosexuals $†$ and overall HIV prevalence in women giving birth. (*Excludes HIV infected attendees who were previously diagnosed. †Attendees at 15 GUM clinics in England, Wales, and Northern Ireland (seven in London, eight elsewhere). ‡Acute STI is defined as presenting with one of the following diagnoses: infectious syphilis, gonorrhoea, chancroid/donovanosis/LGV, chlamydia, NSU, trichomoniasis, scabies/pediculosis, HSV/HPV first attack or molluscum contagiosum. §Through unlinked anonymous testing of neonatal dried blood spots.) Data source: Unlinked Anonymous Programme. 
Table 1 Subcategory of HIV infections diagnosed in the United Kingdom that were probably acquired heterosexually, 19922002

\begin{tabular}{|c|c|c|c|c|c|c|c|c|c|c|c|}
\hline Heterosexual subcategory & $\begin{array}{l}1992 \text { or } \\
\text { earlier }\end{array}$ & 1993 & 1994 & 1995 & 1996 & 1997 & 1998 & 1999 & 2000 & $2001^{*}$ & $2002^{*}$ \\
\hline \multicolumn{12}{|c|}{ Exposure to "high risk" partner(s) infected through: } \\
\hline Male homosexual intercourse & 109 & 24 & 21 & 12 & 11 & 10 & 11 & 12 & 13 & 23 & 17 \\
\hline Injecting drug use & 199 & 37 & 31 & 41 & 33 & 49 & 48 & 23 & 22 & 36 & 16 \\
\hline Blood/blood products & 75 & 5 & 2 & 4 & 9 & 6 & 4 & 5 & 2 & 4 & 3 \\
\hline \multicolumn{12}{|c|}{$\begin{array}{l}\text { Exposure to presumed heterosexually infected partner(s): } \\
\text { Exposure abroad }\end{array}$} \\
\hline in Africa & 1938 & 506 & 534 & 559 & 549 & 642 & 745 & 994 & 1478 & 2151 & 2338 \\
\hline in Latin America/Caribbean & 62 & 24 & 27 & 14 & 25 & 28 & 32 & 62 & 67 & 82 & 108 \\
\hline in Asia & 66 & 28 & 18 & 39 & 44 & 53 & 78 & 76 & 110 & 97 & 95 \\
\hline in North America & 56 & 16 & 9 & 8 & 8 & 10 & 15 & 7 & 6 & 9 & 4 \\
\hline in Europe & 127 & 38 & 36 & 42 & 42 & 50 & 42 & 49 & 46 & 46 & 41 \\
\hline in Australasia & 6 & 2 & 0 & 2 & 1 & 2 & 4 & 6 & 2 & 5 & 2 \\
\hline in country(ies) not known & 24 & 0 & 0 & 2 & 7 & 3 & 17 & 0 & 2 & 1 & 1 \\
\hline \multicolumn{12}{|c|}{ Exposure in the UK to partner(s) presumed infected } \\
\hline outside Europe & 91 & 17 & 38 & 48 & 42 & 71 & 81 & 90 & 127 & 155 & 153 \\
\hline within Europe & 108 & 42 & 44 & 38 & 29 & 39 & 41 & 48 & 47 & 51 & 35 \\
\hline in country(ies) not known & 152 & 28 & 30 & 32 & 28 & 31 & 25 & 30 & 27 & 56 & 87 \\
\hline \multicolumn{12}{|c|}{ Partner(s) exposure category undetermined: } \\
\hline Investigation continuing/closed & 24 & 2 & 6 & 10 & 7 & 11 & 17 & 25 & 32 & 113 & 252 \\
\hline Total & 3037 & 769 & 796 & 851 & 835 & 1005 & 1160 & 1427 & 1981 & 2829 & 3152 \\
\hline
\end{tabular}

*Numbers for recent years will rise as further reports are received. The table will include some records of (a) the same individuals, which are unmatchable because of differences in the information supplied and (b) individuals who left the United Kingdom at some date after diagnosis.

Data source: HIV/AIDS Reports. Reports received by the end of June 2003.

in the United Kingdom, of whom 15200 (31\%) were unaware of their infection. There were 5542 new HIV diagnoses reported for 2002: double the 2735 diagnoses in 1997.

At the end of 2002, overall HIV prevalence among homo/ bisexual men in the United Kingdom was estimated at 7\%, with estimates of total prevalent infections indicating that 22600 homo/bisexual men were infected with HIV, of whom $5500(24 \%)$ were unaware of their infection. Of the newly diagnosed HIV infections that were acquired in the United Kingdom, 80\% (1500/1850) were among homo/bisexual men. The UA GUM survey found 4\% (27/672) of homo/bisexual men aged under 25 in London had a previously undiagnosed HIV infection in 2002, indicating continuing transmission in this population (fig IA). Annual incidence in GUM attendees, measured using STARHS, rose to approximately $3.5 \%$ in $2002 .^{26}$

However, the recent increases in reports of new HIV diagnoses have largely been driven by heterosexually acquired infections, which accounted for 57\% (3152/5542) of all those reported in 2002. Of these infections, three quarters (2338/3152) were probably acquired in Africa (table 1). Estimates of the total prevalent infections indicate that by the end of 2002, 15400 African heterosexuals aged over 15 were living with HIV in the United Kingdom, of whom 4800 (31\%) were undiagnosed.

In 2002, one third (1850/5542) of new HIV diagnoses were probably acquired in the United Kingdom. Although $80 \%$ (1500) of these infections were diagnosed in homo/bisexual men, since 1997 there has been a steady increase in the number of diagnoses of heterosexually acquired HIV infection in the United Kingdom. In 2002, 275 such HIV infections were diagnosed compared to 141 in 1997 (table 1); 56\% (153/ 275 ) of these diagnoses were acquired through partners who were probably infected outside Europe. In England, Wales, and Northern Ireland, although remaining low, the prevalence of previously undiagnosed HIV infection rose significantly among UK born heterosexual males from $0.12 \%(30 / 24465)$ to $0.3 \%(72 / 24040)$ between 1997 and $2002(\mathrm{p}<0.0001)$; prevalence in UK born women was unchanged.
Major acute STI diagnoses reported through KC60 returns have continued their rising trend since the mid-1990s. From 1997 to 2002, there was a $103 \%$ increase to 82206 chlamydia diagnoses (rates were 138/100 000 in males and 167/100 000 in females); a $97 \%$ increase to 24958 gonorrhoea diagnoses (males: 66/100 000, females: 167/100 000); a 716\% increase to 1232 syphilis diagnoses (males: 4/100 000, females: 0.5/ $100000)$; a $9 \%$ increase to 69449 genital warts diagnoses (males: 141/100 000, females: 118/100 000); and a 17\% increase to 18379 genital herpes diagnoses (males: 26/ 100 000, females: 42/100 000) in England, Wales, and Northern Ireland. Laboratory reports of STIs have also increased recently in Scotland; 12392 chlamydia positive isolates were reported in 2002, a $16 \%$ increase on 2001 (10 636).
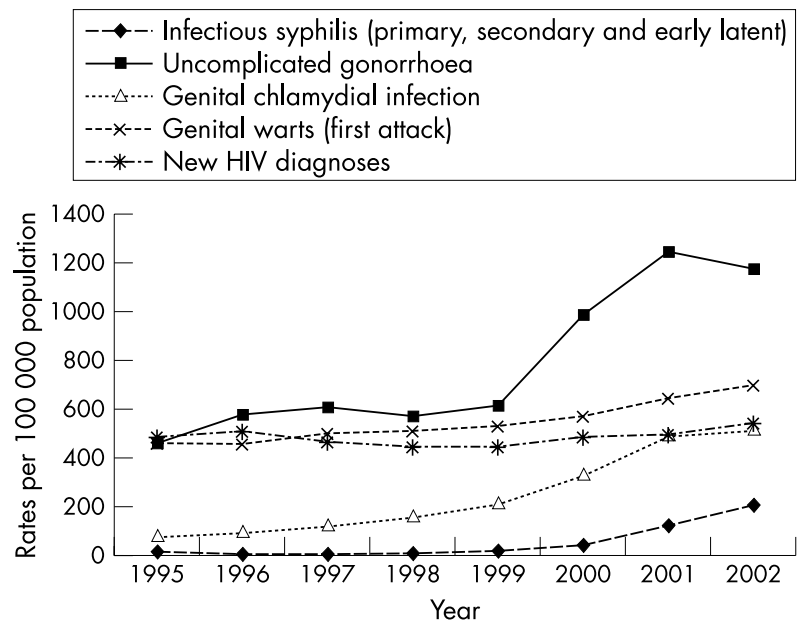

Figure 2 Trends in rates of major acute STIs in homo/bisexual men*, United Kingdomt, 1995-2002. ("Rates are based on an estimated population of 310000 homo/bisexual men resident in England, Wales, and Scotland. ${ }^{25}+2001$ and 2002 data not available for Scotland for KC60 and ISD(D)5 data.) Data sources: KC60 statutory returns and ISD(D) 5 data, and HIV/AIDS Reports, reports received by the end of June 2003. 

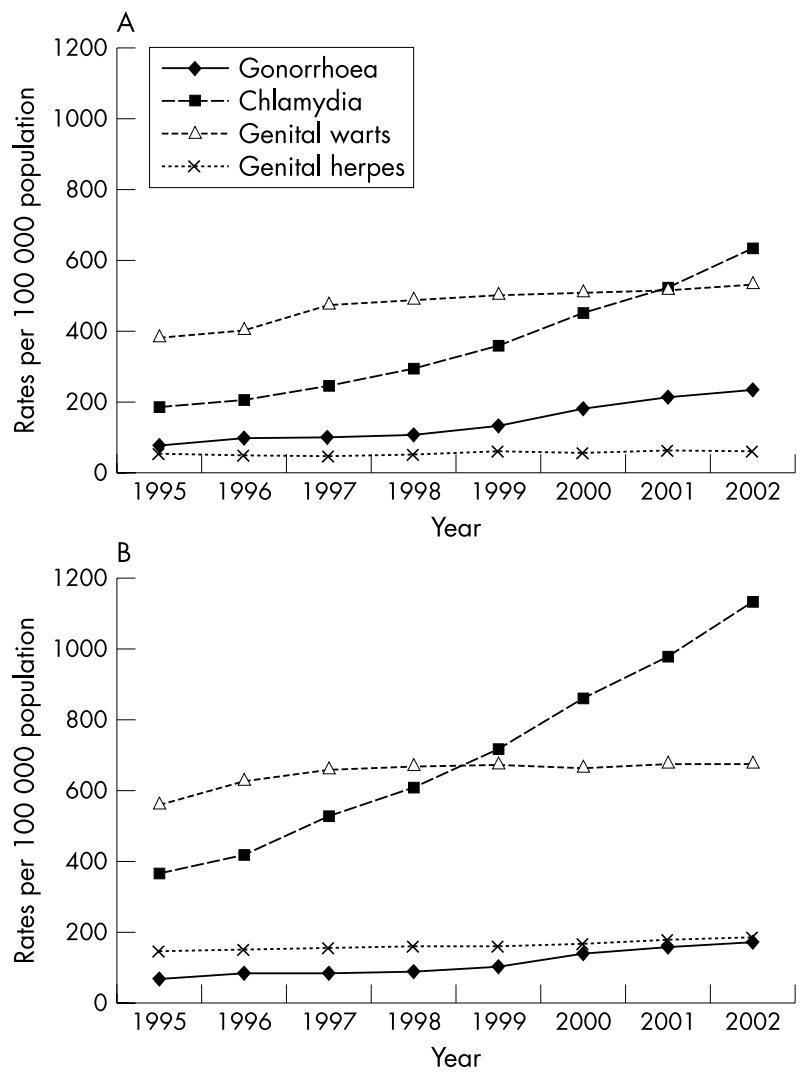

Figure 3 Trends in the rates of selected acute STIs in young females and males aged 16-24 in the United Kingdom*, 1995-2002. (A) Males. (B) Females. (*2001 and 2002 data not available for Scotland.) Data source: KC60 Statutory returns and ISD(D) 5 data.

STIs have risen markedly among homo/bisexual men (fig 2). In this population, cases of gonorrhoea have almost doubled from 1842 in 1999 to 3363 in 2002, and cases of syphilis have increased from 52 to 607 over the same period; this latter rise is as a result of ongoing outbreaks in urban centres in the United Kingdom. ${ }^{22}$

Among heterosexuals, young people and black minority communities continue to be disproportionately represented in STI statistics. Rates of diagnoses of chlamydia in GUM clinics have increased by $215 \%$ in women aged 16-24, from $529 / 100000$ in 1997 to $1135 / 100000$ in 2002 in England, Wales, and Northern Ireland (fig 3). In the 2002 GRASP data collection, black ethnic groups, mainly black Caribbeans, accounted for 55\% (516/936) and 44\% (249/563) of gonococcal isolates collected from heterosexual males and females respectively (fig 4).

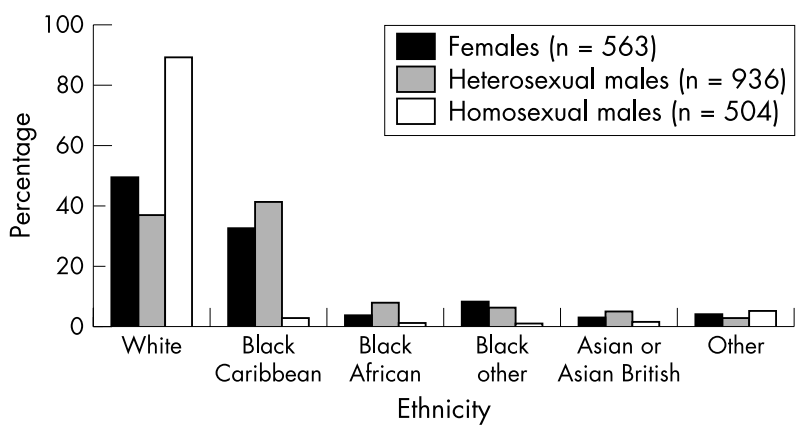

Figure 4 Proportion of new diagnoses of uncomplicated gonorrhoea by ethnicity, England and Wales, 2002. Data source: Gonococcal Resistance to Antimicrobials Surveillance Programme (GRASP).

\section{POPULATION SUBGROUPS}

\section{Homo/bisexual men}

Since HIV/AIDS reporting began in the United Kingdom in the early 1980s there have been 29890 HIV diagnoses reported in homo/bisexual men, 12284 of whom have progressed to AIDS, and 8761 of whom have died. HIV was the third most commonly diagnosed major STI in homo/ bisexual men in 2002 (fig 2).

In 2002, the UA GUM survey found that $6.5 \%$ (97/1495) of previously undiagnosed HIV infected homo/bisexual men were co-infected with an acute STI; the equivalent figure in Scotland was $2.9 \%$ (12/416) and elsewhere in England, Wales, and Northern Ireland, 3.5\% (25/719). Such individuals are of particular concern since they may be at higher risk of passing on their HIV infection to others. In London, 4\% (27/ 672 ) of homo/bisexual men under 25 years attending GUM clinics had a previously undiagnosed HIV infection a clear indication of continuing HIV transmission at relatively high levels. Application of STARHS found that annual HIV incidence among homo/bisexual men rose to approximately $3.5 \%$ in $2002,{ }^{26}$ compared to $2-3 \%$ from $1995-2001,{ }^{27}$ although this difference is not statistically significant. The highest incidence was seen in those aged 35-44 (5.9\%, 95\% confidence intervals 3.7 to 8.8). This increasing trend occurred in a period when there were intensive health promotion campaigns and when $60-70 \%$ of diagnosed HIV infected homo/bisexual men were on antiretroviral therapy (ARV).

Since 1999, considerable increases in the rate of acute STI diagnoses in homo/bisexual men attending GUM clinics have been observed (fig 2). Rates of gonorrhoea diagnoses doubled between 1999 and 2001, from 612/100 000 to $1242 / 100000$. A slight decrease was observed overall in 2002, but there was no decrease in men aged 16-24 where rates increased from 648/ 100000 in 1999 to $1194 / 100000$ in 2002. In 2002, rates of homosexually acquired infectious syphilis have shown a marked rise since 1999 (616\%). This has been associated with a series of large localised outbreaks in Brighton, Manchester, Newcastle upon Tyne, London, ${ }^{22}$ central Scotland, ${ }^{28}$ and Northern Ireland..$^{29}$ Data collected between April 2001 and September 2003 from the ESS programme indicate that 46\% of homo/bisexual men diagnosed with infectious syphilis in London were co-infected with HIV. Increases in genital chlamydia infections in homo/bisexual men were also observed in 2002, up 144\% since 1999.

\section{Factors influencing transmission}

Behavioural surveillance data among homo/bisexual men in the United Kingdom have demonstrated increases in rates of unprotected anal intercourse (UAI), and specifically, UAI involving HIV discordant or unknown status partners. ${ }^{30}$ Data from Natsal $2000^{25}$ suggest that there have been increases in the prevalence of male homosexual behaviour in the general population, and increases in some high risk behaviours among homosexually active men. ${ }^{31}$ The reasons for this rising risk are unclear. However, continued liberalisation of attitudes towards homosexuality, ${ }^{32}$ and "safer sex" fatigue in the era of ARV, ${ }^{33}$ coupled with expansions in opportunities which facilitate partner acquisition (for example, the internet, saunas $)^{34}$ may be contributing factors.

\section{Young people}

People aged 16-24 accounted for just over 10\% (588/5542) of all reports of new HIV diagnoses in 2002; a proportion that has remained constant over time. Their risk exposure distribution was similar to that of people aged over 24 . Heterosexual HIV acquisition accounted for 63\% (370/588) of new HIV diagnoses in 2002 in those aged 16-24, with the 
majority of individuals $(65 \%, 242 / 370)$ probably infected in Africa.

Rates of STIs have risen markedly among young people (fig 3 ) and this population subgroup bear a disproportionate burden of STI diagnoses. In 2002, women aged 16-24 accounted for $72 \%$ (33 205/46 140) of all female chlamydia diagnoses, 66\% (5031/7569) of gonorrhoea, 62\% (50/137) of syphilis and 61\% (19 792/32 544) of genital warts reported from GUM clinics in England, Wales, and Northern Ireland.

Rates of diagnoses from GUM clinics for chlamydia, gonorrhoea, and genital warts were highest among females aged 16-19 and males aged 20-24. The highest rates of chlamydial diagnoses were seen in women aged 16-19 and men aged 20-24 at 1209 and 842/100 000 respectively. These figures are likely to underestimate the total number of infections because most infections in women are asymptomatic, and thus care and treatment are not sought. Chlamydial infections diagnosed in primary care and other community settings ${ }^{13}$ are not reported in the KC60 returns and also contribute to this underestimation. Of women diagnosed with gonorrhoea, $40 \%$ were under 20 . In men, rates of gonorrhoea were highest in those aged 20-24 in 2002 $(296 / 100000)$, an increase of $231 \%$ since 1997 . Similarly, rates of genital herpes simplex infection remain highest among males and females aged 20-24 (93/100 000 and 296/ 100000 respectively). Unlike other bacterial STIs, rates of syphilis among young people remain low.

\section{Factors influencing transmission}

Young people are behaviourally more vulnerable to STI acquisition as they generally have higher numbers of sexual partners, more concurrent partnerships, and change partners more often than older age groups. ${ }^{35}$ Although consistent and proper use of condoms reduces the risk of STI transmission and unintended pregnancy, many young people may not have developed the skills and confidence to implement this successfully. ${ }^{36}$

STI re-infection is a particular concern in this population. In a study of three GUM clinics, ${ }^{37}$ young age was a key determinant of STI re-infection within a year of initial diagnosis. Studies in the United States have also found that re-infection rates are high among adolescents and young adults, particularly women, ${ }^{38}$ including those aged under $15 .{ }^{39}$

\section{Black and ethnic minority populations}

The number of HIV infected black African adults born in the United Kingdom is increasing but currently remains low. It is estimated that in 2002, black African adults accounted for $63 \%$ (15 400) of the total of prevalent HIV infections in heterosexuals, and $51 \%(4800)$ of heterosexuals who are unaware of their HIV infection. In 2002, of the 12203 HIV infected heterosexuals reported to SOPHID, 68\% (8262) of those for whom ethnicity was reported were black African (a $330 \%$ increase since 1997), 4\% (501) black Caribbean, and $21 \%$ (2580) white. The UA pregnant women surveys found an HIV prevalence of 2.5\% (239/47 075) in women born in subSaharan Africa who gave birth in 2002. This compares with a prevalence of $0.03 \%(42 / 121833)$ in their UK born counterparts (fig 1B). These data reflect the focus of the HIV pandemic in sub-Saharan African countries and the impact of population movement on the UK statistics.

Undiagnosed HIV infection continues to be a feature of the treatment histories of black heterosexuals. Among subSaharan born heterosexuals included in the UA GUM survey, the prevalence of previously undiagnosed HIV infection rose to $4.2 \%(159 / 3752)$ in London and $7.9 \%(60 / 757)$ outside London (fig 1B). The latter figure may be due to the recent dispersal to areas outside London of migrant populations originating from high HIV prevalence countries. In Scotland, the prevalence of previously undiagnosed HIV infection was
$5.7 \%(9 / 157)$ in heterosexuals of African nationality, compared to $0.1 \%(13 / 133314)$ in heterosexuals of British nationality.

STI diagnoses disproportionately fall on the United Kingdom's black minority populations. ${ }^{40}{ }^{41}$ In the 2002 GRASP $^{23}$ data collection (fig 4), black ethnic groups, mainly black Caribbean, accounted for 55\% (516/936) and 44\% (249/ 563 ) of gonococcal isolates in heterosexual males and females respectively. The ESS programme in London revealed that $48 \%$ (187/393) of heterosexual syphilis diagnoses were among black or black British ethnic groups.

\section{Factors influencing transmission}

Black and ethnic minority populations in the United Kingdom continue to have poor sexual health. However, few behavioural surveys give insight into sexual health among ethnic minority groups. Variations in the burden of STIs among these populations are known to be influenced by a number of behavioural and social factors. ${ }^{42}$ Qualitative community based studies highlight variations in sexual socialisation, attitudes and community norms related to sexual behaviour; sex, religious beliefs, and degree of acculturation are all influential factors. ${ }^{43}$ Although qualitative studies suggest that variations in high risk behaviour do exist across ethnic groups, ${ }^{44}{ }^{45}$ these alone cannot explain the observed disparities. Factors such as patterns of sexual mixing, differential access to curative services, and background disease prevalence in the communities concerned may also be contributing. ${ }^{42}{ }^{46}$ Data from population based surveys and mathematical modelling will be needed to further elucidate these associations.

\section{HIV SCREENING AND TREATMENT}

There has been some success in interventions aimed at reducing HIV transmission in the United Kingdom. Diagnosis at an earlier stage of HIV infection presents the opportunity for treatment to postpone further illness and to reduce viral load which, along with changes in sexual behaviour, may reduce the risk of onward HIV transmission.

The number of GUM clinic attendees accepting a voluntary confidential HIV test (VCT) can be measured through the UA GUM survey, which collects KC60 data in addition to limited demographic information. Voluntary confidential HIV testing (VCT) has increased in homo/bisexual men and heterosexuals respectively, from 45\% (2724/6019) and 25\% (16 886/ $66880)$ in 1997, to $62 \%(4604 / 7372)$ and 54\% (40 746/ 74935 ) in 2002 in England, Wales, and Northern Ireland. From 2003, modified KC60 data will allow better monitoring of VCT uptake. In Scotland, data indicate that uptake of VCT has increased in homo/bisexual men and heterosexuals respectively, from $47 \%$ (454/959) and 23\% (2624/11 223) in 1997 , to $59 \%(761 / 1290)$ and $36 \%(5142 / 14281)$ in 2002.

Similarly, over recent years, CD4 surveillance data show a recent trend towards earlier diagnosis for homo/bisexual men. Only $24 \%$ of homo/bisexual men had a CD4 cell count less than 200 cells $\times 10^{6} / 1$ at HIV diagnosis (an indicator of a "late diagnosis") in 2002 compared to $28 \%$ in 1997. In contrast, $43 \%$ of newly diagnosed heterosexuals had a "late diagnosis" in 2002. This may be because a high proportion of heterosexuals were infected, and previously lived abroad. Additionally, heterosexuals may perceive themselves to be at lower risk from HIV and may present for testing only when they become symptomatic. ${ }^{47} 48$

In England, the proportion of HIV infected pregnant women remaining undiagnosed by the time of delivery has declined since the introduction of the universal offer and recommendation of an HIV test as a routine part of antenatal care in 1999 ${ }^{49}$; ; this policy has now been introduced elsewhere in the United Kingdom. 
In 2002 there were an estimated 686 births to HIV positive women in England, Wales and Scotland, of whom at least $79 \%$ (539/686) were reported as diagnosed before delivery. Overall, HIV detection rates in 2002 are currently estimated at $75 \%$ (318/422) for London, 85\% (199/234) elsewhere in England and Wales and 73\% (22/30) in Scotland (fig 5). These minimum estimates are subject to reporting delay and are likely to rise as more diagnosed infections in pregnancies are reported.

These improved maternal HIV detection rates have reduced the proportion of exposed children who go on to acquire the infection vertically. In London, in 2002 (based on the current estimated detection rates), the estimated proportion of children exposed to HIV vertically who were themselves infected was 8\% (35/422) compared with 19\% (37/200) in 1997. In the rest of the United Kingdom this proportion decreased from $22 \%(25 / 113)$ in 1997 to $6 \%(16 / 264)$ in 2002.

A high proportion of HIV infected people who were eligible for ARV were on medication in 2002 in the United Kingdom. Of the 1708 homo/bisexual men with CD4 counts of 200 cells $\times 10^{6} / 1$ or less, $78 \%$ were on therapy; of the 2433 heterosexuals, $78 \%$ were on therapy; and of the 211 IDUs, $73 \%$ were on therapy (measured through SOPHID). Equivalent figures

Proportion of infants exposed who become infected with HIV

Proportion of HIV infected pregnant women diagnosed before delivery $^{\star}$
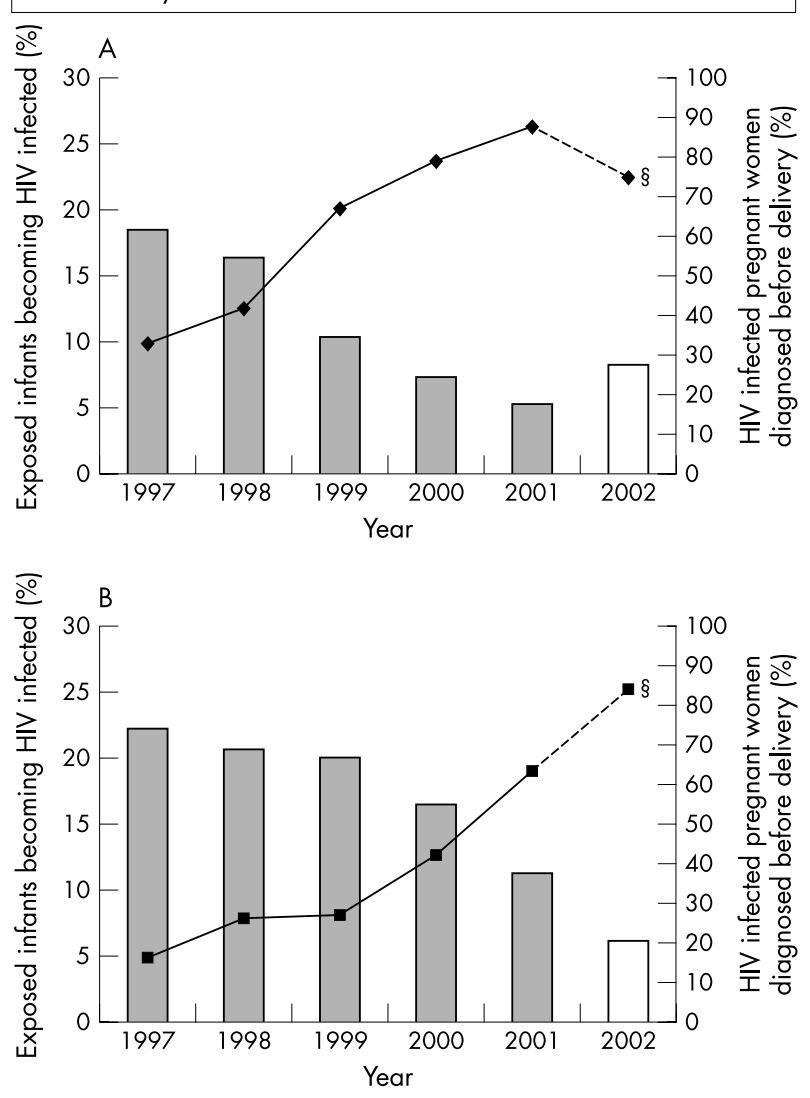

Figure 5 Estimated proportion of HIV infected women diagnosed before delivery* and of exposed children becoming infected with HIV†‡, 1997-2002. (A) London. (B) Outside London-England, Wales, and Scotland. ("Includes those previously diagnosed and those diagnosed through antenatal testing. †Assumes a vertical transmission rate of $26.5 \%$ in undiagnosed women and $2.2 \%$ in diagnosed women. ${ }^{53} \pm$ These data contain reports received by the end of September 2003. §Data for 2002 should be considered preliminary minimum estimates, and as the number of reports rise, estimates of infants becoming HIV infected will fall.) Data source: Unlinked Anonymous Programme and the National Study of HIV in Pregnancy and Childhood (NSHPC). were higher for Scotland: 92\% (72, p=0.006), 94\% (84, $\mathrm{p}=0.0004)$, and $92 \%(98, \mathrm{p}=0.0002)$. However, in Scotland ARV therapy is measured through CD4 monitoring which is largely undertaken to assess a patients eligibility for ARV. These data confirm that exposure group does not affect the level of therapy uptake.

\section{DISCUSSION}

The surveillance data confirm that HIV and other STIs have increased within the UK population. Population subgroups that have high rates of sexual partner change continue to have higher infection rates, in particular HIV and STIs among homo/bisexual men and STIs among young people. Black and ethnic minority populations (including subgroups born in high prevalence countries) are disproportionately affected by poor sexual health. There is some evidence of onward HIV transmission rising within the United Kingdom though as yet this is limited.

Health promotion campaigns, targeted HIV and chlamydia screening initiatives, and increased sensitivity of diagnostic tests may all have played a part in the rising number of HIV and STI diagnoses reported in 2002. The well documented pressure mounting upon GUM clinics ${ }^{3}$ through increased numbers of high risk patients attending has undoubtedly contributed to the observed trends. Since KC60 returns data are aggregate, it is not possible to determine what proportion of attendees are re-attending for follow up and/or are becoming re-infected. A disaggregate STI surveillance system is currently under development and will help interpretation of future trends.

STI diagnoses are mainly reported through GUM clinics and voluntarily from NHS laboratories. The former misses cases diagnosed in other settings and the latter reports are incomplete. This combined with the requirement for data accuracy over data quantity may have led to a general underestimate of HIV and STI diagnoses in the United Kingdom.

Indications from Natsal $2000^{25}$ of increasing high risk behaviour (including concurrent partnerships and higher rates of partner acquisition), the continuing immigration of heterosexuals from countries of high HIV prevalence, and the suggested rising of HIV incidence, undiagnosed HIV infection, and STI diagnoses in homo/bisexual men all indicate that sexual health is deteriorating and the documented increases are real.

Through national collaboration, high levels of data reporting, analysis and feedback performed in conjunction within a complementary set of UK surveillance systems, allow the data to be used as a powerful tool in providing information for action. The role of surveillance has been instrumental in the creation and monitoring of successful initiatives such as the introduction of the universal offer and recommendation of an HIV test in pregnant women. ${ }^{49} 50$

Our data confirm the need for national and local prioritisation of sexual health and HIV prevention activities. Interventions such as those outlined in the English Sexual Health and HIV Strategy ${ }^{4}$ need to be implemented urgently. For homo/bisexual men this includes HIV/STI education, promotion of safer sex and HIV testing, and increasing the uptake of hepatitis B vaccination in GUM clinics. The strategy has also specifically identified young people as a priority group for action and the Department of Health is currently implementing a range of interventions including the National Chlamydia Screening Programme. The persistent ethnic disparities in sexual health outcomes deserve even greater attention, particularly with emerging evidence of increasing HIV transmission within the United Kingdom among black communities. The disaggregate STI surveillance system currently under development ${ }^{51}$ will allow ethnic disparities 


\section{Key messages}

- Prevalence of HIV infection in the United Kingdom is increasing; an estimated 49500 adults aged over 15 were living with HIV in the United Kingdom in 2002, of whom $31 \%$ were unaware of their infection

- While many newly diagnosed heterosexual cases are thought to have acquired their infection overseas, there is evidence of continuing transmission of HIV in the United Kingdom, particularly among homo/bisexual men

- New diagnoses of major acute STIs have risen in the past 5 years, with rates highest in homo/bisexual men and young people

- Effective surveillance is essential to provide timely information on the changing epidemiology of HIV and other STls in the United Kingdom

in sexual health to be monitored in the future and will facilitate the determination of where preventive efforts need to be targeted. In the meantime, key interventions for prioritisation include improving access to treatment and care services in hyperendemic areas; raising community HIV/STI awareness; and enhancing secondary prevention actives including partner notification. ${ }^{42}$

Elsewhere in the United Kingdom, health promotion campaigns aimed at high risk subgroups are being implemented and will undoubtedly require scaling up in the near future. In Wales, for example, the "Come Clean" multimedia campaign has been run by $\mathrm{BBC}$ Wales and the Welsh Assembly and is targeted at young people. ${ }^{52}$ Effective secondary prevention activities are also needed to tackle the growing problem of STI re-infection and epidemiological synergy between STIs and HIV infection. Such initiatives need to be fully supported and sustained if further deterioration in the United Kingdom's sexual health is to be prevented. Finally, although the impact of these initiatives can only be recognised over many years it is important that medium and long term targets are set and progress monitored to ensure the most appropriate, cost effective, and efficient use of scarce resources.

Further information on HIV/STI surveillance trends can be found in a report published by the Health Protection Agency and others: Health Protection Agency, SCIEH, ISD, National Public Health Service for Wales, CDSC Northern Ireland and the UASSG. Renewing the focus. HIV and other Sexually Transmitted Infections in the United Kingdom in 2002. London: Health Protection Agency November 2003 ${ }^{12}$ (www.hpa.org.uk/infections/topics_az/hiv_and_sti/publications/annual2003/annual2003.pdf).

\section{ACKNOWLEDGEMENTS}

We extend our thanks to everybody who contributed to the writing of the annual report: Renewing the Focus: Tim Chadborn, Glenn Codere, Leah de Souza, Sarah Dougan, Gillian Elam, Josh Forde, John Harris, Vivian Hope, Alisha Johnston, Louise Logan, Catherine Lowndes, Neil MacDonald, Helen Munro, Bela Patel, Lara Payne, Brian Rice, Elizabeth Rudd, Ian Simms, and Katy Sinka.

We gratefully acknowledge the continuing collaboration of the Sexually Transmitted and Blood Borne Viruses Laboratory, Specialist and Reference Microbiology Division, Health Protection Agency, and of clinicians, microbiologists, immunologists, public health practitioners, occupational health doctors and nurses, and other colleagues who contribute to the surveillance of HIV and STIs in the United Kingdom.

We would like to thank our collaborating centres for HIV and AIDS surveillance in the UK: The Scottish Centre for Infection and
Environmental Health; The Institute of Child Health (London); The UK Haemophilia Centres Doctors Organisation; members of the Scottish ISD(D) 5 Collaborative Group; Collaborators on the Unlinked Anonymous Programme (a full list of collaborators available at www.hpa.org.uk/infections/topics_az/hiv_and_sti/hiv/epidemiology/ ua.htm).

Finally, we thank Philip Mortimer for commenting on this paper and we are also grateful to colleagues at the UK Departments of Health both for funding specific surveys and for helpful comments on this paper at draft stage.

\section{CONTRIBUTORS}

$\mathrm{AB}$, ST with KS, CM, SLM, and GM, analysed the data from the Unlinked Anonymous Surveys, HIV/AIDS reports, prevalence estimates and behavioural surveillance, STI surveillance, and STARHS respectively with support from BG, NG, FN, and KF; DG, DT, and BS analysed and are responsible for data from the Scottish Centre Infection and Environmental Health, the National Public Health Service for Wales, CDSC, and the Health Protection Agency, CDSC, Northern Ireland respectively; PT coordinates the National Study of HIV in Pregnancy and Childhood and collaborated with the analysis of the Unlinked Anonymous Pregnant Women Surveys; NG is the programme manager and is responsible for data from the Unlinked Anonymous Programme; BG is responsible for data from HIV/AIDS reports; and FN is responsible for data from the unlinked anonymous surveys of Pregnant Women. JP is responsible for laboratory aspects for the Unlinked Anonymous Surveys and assisted with the interpretation of data; all authors were involved in interpretation of the results and drafting the paper; $\mathrm{AB}$ undertook the main writing of the paper.

\section{Authors' affiliations}

A E Brown, K E Sadler, S E Tomkins, C A McGarrigle, D S LaMontagne, B G Evans, O N Gill, F Ncube, K A Fenton, HIV and STI Department, Health Protection Agency, Communicable Disease Surveillance Centre, UK

D Goldberg, The Scottish Centre for Infection and Environmental Health, UK

P A Tookey, Institute of Child Health (ICH), University College London, UK

B Smyth, Health Protection Agency, Communicable Disease Surveillance Centre (Northern Ireland), UK

D Thomas, National Public Health Service for Wales, Communicable Disease Surveillance Centre, UK

G Murphy, JV Parry, The Sexually Transmitted and Blood Borne Viruses Laboratory, Specialist and Reference Microbiology Division, Health Protection Agency, UK

K A Fenton, The Centre for Sexual Health and HIV Research, Department of Primary Care and Population Sciences, Royal Free and University College Medical School, London, UK

\section{REFERENCES}

1 Nicoll A, Hamers FF. Are trends in HIV, gonorrhoea and syphilis worsening in Western Europe? BMJ 2002;324:1324-7.

2 Adler MW. A survey of STI policies and progress in Europe. Sex Transm Infect 2003;79:171.

3 Diuretic T, Catchpole M, Bingham JS, et al. Genitourinary medicine services in the United Kingdom are failing to meet current demand. Int J STD AIDS $2001 ; 12: 571-2$.

4 Department of Health. The national strategy for sexual health and HIV implementation action plan. London: Department of Health, 2002.

5 Department of Health. Press Release. Health minister announces group to advise on sexual health. London: DoH, 6 March 2003. Available at www.doh.gov.uk/sexualhealthandhiv/pdfs/press_release_6march2003.pdf

6 The National Assembly for Wales. A strategic framework for promoting sexual health in Wales. Cardiff: National Assembly for Wales, The Health Promotion Division, 2000.

7 Scottish Executive. Enhancing sexual wellbeing in Scotland. A sexual health and relationship strategy. Edinburgh: Scottish Executive, 2003 October.

8 Department of Health, Social Services and Public Safety (DHSSPS). Sexual health promotion strategy and action plan consultation document, Northern Ireland. DHSSPS, 2003 December.

9 House of Commons Health Committee. Sexual health. Third report of session 2002-03. London: Stationary Office, 11 June 2003.

10 All-Party Parliamentary Group on AIDS Migration and HIV. Improving lives in Britain. London: APPG-AIDS, 2003 July. Available at www.appgaids.org.uk/Publications/

Migration\%20and\%20HIV\%2Olmproving\%20Lives.pdf 
11 Government response to the Health Select Committee's Third Report of the Session 2002/03 on Sexual Health. London: HMSO, 2003. Available at www.doh.gov.uk/sexualhealthandhiv/pdfs/ response to health select comm three.pdf

12 Health Protection Agency, SCIEH, ISD, National Public Health Service for Wales, CDSC Northern Ireland and the UASSG. Renewing the focus. HIV and other sexually transmitted infections in the United Kingdom in 2002. London: Health Protection Agency, November, 2003.

13 Fenton KA, Korovessis C, Johnson AM, et al. Sexual behaviour in Britain: reported sexually transmitted infections and prevalent genital Chlamydia trachomatis infection. Lancet 2001:358:1851-4.

14 PHLS Communicable Disease Surveillance Centre, ICH (London), SCIEH, HIV and AIDS in the UK. An epidemiological review: 2000. London: PHLS Communicable Disease Surveillance Centre, 2001.

15 McHenry A Macdonald N, Sinka K, et al. National assessment of prevalence diagnosed HIV infections Commun Dis Public Health 2000;3:77-81.

16 Gupta SB, Dingley SD, Lamagni TL, et al. The national CD4 surveillance scheme for England and Wales. Commun Dis Public Health $2001 ; 4: 27-32$

17 Nicoll A, Gill ON, Peckham CS, et al. The public health applications of the unlinked anonymous seroprevalence monitoring programme for HIV in the United Kingdom. Int J Epidemiol 2000;29:1-10.

18 Catchpole MA, McGarrigle CA, Rogers PA, et al. Serosurveillance of prevalence of HIV infection in homosexual men with acute sexually transmitted infection. BMJ 2001;321:1318-20.

19 Janssen RS, Satten GA, Rawal BD, et al. New testing strategy to detect early HIV-1 infection for use in incidence estimates and for clinical and prevention purposes. JAMA 1998;280:42-8

20 Ades AF, Davison CF, Holland FJ, et al. Vertically transmitted HIV infection in the British Isles. BMJ 1993;306:1296-99.

21 Cliffe S, Tookey PA, Nicoll A. Antenatal detection of HIV: national surveillance and unlinked anonymous survey. BMJ 2001;323:376-7.

22 Doherty L, Fenton KA, Jones J, et al. Syphilis: old problem, new strategy. BMJ 2002;325:153-6.

23 Fenton KA, Ison C, Johnson AP, et al. GRASP Collection. Ciprofloxacin resistence in Neisseria gonorrhoeae in England and Wales in 2002. Lancet 2003;362:495

24 Petruckevitch A, Nicoll A, Johnson AM, et al. Direct estimates of prevalence HIV infection in adults in England and Wales for 1991 and 1993: an improved method. Genitourin Med 1997;73:348-54.

25 Johnson AM, Mercer CH, Erens B, et al. Sexual behaviour in Britain: partnerships, practices and HIV risk behaviours. Lancet 2001;358:1835-42.

26 Murphy G, Charlett A, Brown AE, et al. Is HIV incidence increasing in homo/ bisexual men attending GUM clinics in England, Wales and Northern Ireland. Commun Dis Public Health 2004;7:11-14.

27 Murphy G, Charlett A, Jordan LF, et al. HIV incidence appears constant in men who have sex with men despite the widespread use of effective antiretroviral therapy AIDS 2004;18:265-72.

28 Redman C. Sharp increase in reports of infectious syphilis in Scotland in 2002 Eurosurveillance 2003;7:(5).

29 Lynch A, Smyth B. Syphilis outbreak in Northern Ireland. Eurosurveillance 2003;7:(24)

30 Dodds J, Mercey D. Sexual health survey of gay men-London 2002: summary of results. London: Royal Free and University College Medical School, 2003.

31 Johnson AM, Dodds J, Mercer CH, et al. HIV changing patterns of male homosexual behaviour in Britain: comparative analysis of independen community and national probability samples (Natsal) 1990-2001. Oral presentation at IUSTI-Europe 2002 18th Congress on Sexually Transmitted Infections. Vienna, 12-14 September 2002

32 Copas AJ, Wellings K, Erens B, et al. The accuracy of reported sensitive sexual behaviour in Britain: exploring the extent of change 1990-2000. Sex Transm Infect 2002;78:26-30.

33 Ostrow DE, Fox KJ, Chmiel JS, et al. Attitudes towards highly active antiretroviral therapy are associated with sexual risk taking among HIVinfected and uninfected homosexual men. AIDS 2002;16:775-80.

34 McFarlane M, Bull SS, Rietmeijer CA. The Internet as a newly emerging risk environment for sexually transmitted diseases. JAMA 2000;284:443-6.

35 Wellings K, Nanchahal K, Macdowall W, et al. Sexual behaviour in Britain: early heterosexual experience. Lancet 2001;358:1843-50.

36 Burack R. Teenage sexual behaviour: attitudes towards and declared sexual activity. Br J Fam Plan 1999;24:145-8.

37 Hughes G, Brady AR, Catchpole MA, et al. Characteristics of those who repeatedly acquire sexually transmitted infections: a retrospective cohort study of attendees at three urban sexually transmitted disease clinics in England. Sex Transm Dis 2001;28:379-86.

38 Orr PO, Johnston K, Brezendine E, et al. Subsequent sexually transmitted infection in urban adolescents and young adults. Arch Pediatr Adolesc Med $2001 ; 155: 947-53$

39 Hillis SD, Nakashima A, Marchbanks PA, et al. Risk factors for recurrent Chlamydia trachomatis infections in women. Am J Obstet Gynecol 1994; 170:801-6.

40 Shahmanesh M, Gayed S, Ashcroft M, et al. Geomapping of chlamydia and gonorrhoea in Birmingham. Sex Transm Infect 2000;76:268-72.

41 Low N, Sterne JA, Barlow D. Inequalities in rates of gonorrhoea and chlamydia between black ethnic groups in south east London: cross sectional study. Sex Transm Infect 2001;77:15-20.

42 Fenton KA. Strategies for improving sexual health in ethnic minorities. Curr Opin Infect Dis 2001;14:63-9.

43 Elam G, Fenton KA, Johnson AM, et al. Exploring ethnicity and sexual health SCPR Publications, 1999

44 Evans BA, Bond RA, Macrae KD. Sexual behaviour in women attending a genitourinary medicine clinic. 1988. Sex Transm Infect 2000;76(Suppl 1): S41.

45 Evans BA, Bond RA, MacRae KD. Sexual behaviour and sexually transmitted infection among African and Caribbean men in London. Int J STD AIDS 1999;10:744-8.

46 Low N, Connell P, McKevitt C, et al. "You can't tell by looking": pilot study of a community-based intervention to detect asymptomatic infections. Int J STD AIDS 2003; 14:830-4.

47 Burns FM, Fakoya AO, Copas AJ, et al. Africans in London continue to present with advanced HIV disease in the era of highly active antiretroviral therapy. AIDS 2001;15:2453-5

48 Del Amo J, Petruckevitch A, Phillips AN, et al. Disease progression and survival in HIV-1 infected Africans in London. AIDS 1998;12:1203-9.

49 Department of Health. Targets aimed at reducing the number of children born with HIV: report from an expert group. London: DoH, 1999

50 NHS Executive. Reducing mother to baby transmission of HIV. Health Service Circular 1999/183. London: Department of Health, 1999.

51 PHLS, DHSS\&PS and the Scottish ISD(D)5 Collaborative Group. Sexually transmitted infections in the UK: new episodes seen at genitourinary medicine clinics, 1991-2001. London: Public Health Laboratory Service, 2002.

52 BBC Wales and the Welsh Assembly. www.bbc.co.uk/wales/comedean/

53 Duong T, Ades A, Gibb DM, et al. Vertical transmission rates for HIV in the British Isles: estimates based on surveillance data. BMJ 1999;319:1227-9. 